\title{
Estabelecimento da leptospirose por infecção experimental em hamsters (Mesocricetus auratus) com Leptospira interrogans sorovar Canicola, estirpe LO4, por exposição cutânea integra e com abrasões
}

\author{
Development of the leptospirosis by experimental infection in hamsters (Mesocricetus auratus) \\ with Leptospira interrogans serovar Canicola, strain LO4, by intact and scratched skin exposures
}

Carolina de Sousa Américo BATISTA ${ }^{1}$; Sérgio Santos de AZEVEDO²; Sílvio Arruda VASCONCELLOS ${ }^{1}$; Vanessa CASTRO ${ }^{3}$; Salomão Moreira de FIGUEIREDO²; Clebert José ALVES²; Flávia Carolina Souza de OLIVEIRA $^{1}$; Margareth Élide GENOVEZ ${ }^{3}$

${ }^{1}$ Departamento de Medicina Veterinária Preventiva e Saúde Animal. Faculdade de Medicina Veterinária e Zootecnia da Universidade de São Paulo, São Paulo-SP

${ }^{2}$ Unidade Acadêmica de Medicina Veterinária do Centro de Saúde e Tecnologia Rural da Universidade Federal de Campina Grande, Patos-PB

${ }^{3}$ Centro de Pesquisa e Desenvolvimento em Sanidade Animal do Instituto Biológico, São Paulo-SP

\begin{abstract}
Resumo
O estabelecimento e a evolução da leptospirose em hamster (Mesocricetus auratus) pela infecção experimental com Leptospira interrogans sorovar Canicola, estirpe LO4, pela exposição cutânea íntegra e escarificada, tendo como controle a via intraperitoneal foram avaliados. Foram utilizados 120 hamsters, fêmeas, distribuídas em dois grupos de acordo com a via de inoculação (pele escarificada e pele íntegra). O inóculo infeccioso foi constituído por uma cultura pura de L. interrogans sorovar Canicola (estirpe LO4), isolada do fígado de um suíno de abatedouro em Londrina, Estado do Paraná e tipificada pela técnica de adsorção de aglutininas com o kit de anticorpos monoclonais no Royal Tropical Institute, Amsterdã, Holanda. Os animais foram observados duas vezes ao dia, durante 21 dias. Os animais que vieram a óbito foram necropsiados e colhidos assepticamente rins, fígado, sistema genital (útero e ovário) e cérebro. Os animais sobreviventes foram eutanasiados após 21 dias. Foram ainda colhidas amostras de soro sanguíneo por punção cardíaca para a pesquisa de aglutininas antileptospiras nos animais sobreviventes, pela técnica de soroaglutinação microscópica (SAM). Para a detecção de leptospiras, foram utilizados microscopia direta a fresco e cultivo microbiológico. A via cutânea escarificada induziu maior letalidade quando comparada com a pele integra, com estabelecimento e evolução da leptospirose. Por outro lado, a via cutânea íntegra induziu mais frequentemente o estado de portador renal e/ou genital para leptospirose. A estirpe LO4 apresentou baixo poder imunogênico, induzindo soroconversão na SAM em apenas um animal.
\end{abstract}

Palavras-chave: Leptospiorose. Infecção experimental. Hamster. Exposição cutânea. Sorovar Canicola (estirpe LO4).

\begin{abstract}
The establishment and evolution ofleptospirosis in hamster (Mesocricetus auratus) by experimental infection with Leptospira interrogans serovar Canicola, LO4 strain, by intact and scratched skin exposures, having as control the intraperitoneal route, were evaluated. Hundred-twenty female hamsters distributed in two groups according to inoculation route (intact and scratched skin) were used. Infectious inoculum was constituted by a pure culture of L. interrogans serovar Canicola (strain LO4), isolated from liver from a slaughtered swine in Londrina, Paraná state and typified by agglutinins adsortion technique with monoclonal antibody kit at the Royal Tropical Institute, Amsterdam, the Netherlands. The animals were observed twice a day during 21 days. Animals that died were necropsied and kidneys, liver, genital tract (uterus and ovaries) and brain were aseptically collected. On the 21 st post-inoculation day, surviving animals were euthanized. In these animals, serum samples were also collected by cardiac puncture to antileptospires agglutinins research using microscopic agglutination test (MAT). Fresh direct microscopy and microbiological culture were used for the detection of leptospires. Scratched skin route induced larger lethality when compared to intact skin route, with establishment and evolution of leptospirosis. On the other hand, intact skin route induced renal and/or genital carrier state more frequently. LO4 strain presented low immunogenic power, characterized by soroconversion at the MAT in only one inoculated animal.
\end{abstract}

Keywords: Leptospiorosis. Experimental infection. Hamster. Skin exposure. Serovar Canicola (LO4 strain).

Correspondência para:

Sérgio Santos de Azevedo

Centro de Saúde e Tecnologia Rural

Unidade Acadêmica de Medicina Veterinária

Universidade Federal de Campina Grande
Av. Universitária, Bairro Santa Cecília, CEP.: 58700-970, Caixa Postal 64,

Patos, Paraíba, Brasil

E-mail: ssazevedo@cstr.ufcg.edu.br

Recebido: 28/04/2009

Aprovado: 04/03/2010 


\section{Introdução}

A leptospirose é uma doença bacteriana infectocontagiosa, de curso agudo ou crônico, de caráter zoonótico e cosmopolita, que acomete o homem e os animais domésticos e silvestres, assumindo considerável importância como problema econômico e de saúde pública. Essa doença é causada por um grande número de espiroquetas morfologicamente e antigenicamente relacionadas do gênero Leptospira spp. e se encontra difundida em quase todos os países. A frequência de apresentação dos diversos sorovares depende da amplitude de deslocamento dos respectivos hospedeiros preferenciais e da intensidade e extensão da produção animal ${ }^{1}$.

Dentre os animais de laboratório usualmente empregados para o estudo da leptospirose, o hamster sírio (Mesocricetus auratus) tem sido um dos mais utilizados $^{2}$. Nesses animais, já foram efetuados estudos de leptospirose experimental ${ }^{3,4}$, da patogênese da doença $\mathrm{a}^{5}$, do tipo de via empregada para a infecção experimental ${ }^{6}$, pesquisa da virulência do agente ${ }^{7}$, do estado de portador ${ }^{8,9}$, da análise de alterações morfológicas em órgãos frente a doenç $\mathrm{a}^{10}$, da avaliação histopatológica do fígado de hamsters gestantes infectadas por leptospiras ${ }^{11}$, do isolamento de leptospiras de tecido renal de hamsters experimentalmente infectados ${ }^{12}$, da presença do agente nos ovários ${ }^{13} \mathrm{e}$ do desenvolvimento de vacinas ${ }^{14,15,16}$.

Estirpes autóctones devem ser estudadas de maneira minuciosa, pois sua condição infectante está diretamente relacionada a fatores ambientais, climáticos e densidade populacional de hospedeiros. Apesar da existência de diversos sorovares e do potencial para estabelecer infecção em uma variedade de hospedeiros, na realidade apenas um pequeno número de sorovares são efetivamente infectantes e causadores de doença na natureza. A estirpe LO4 foi isolada de fígado de dois suínos abatidos em Londrina, Estado do Paraná, Brasil ${ }^{17}$ e tipificada por kit de anticorpos monoclonais (Royal Tropical Institute, Amsterdã, Holanda) como Leptospira interrogans sorovar Canicola.

Em decorrência da grande importância da leptospirose nas criações zootécnicas pelos possíveis prejuízos econômicos, principalmente pelas infecções crônicas, relacionadas aos aspectos reprodutivos e também pela sua importância para a saúde pública, o presente trabalho pretendeu estudar a influência da via cutânea com e sem abrasões no estabelecimento da doença e no estabelecimento do portador renal e/ou genital na leptospirose experimental por Leptospira interrogans sorovar Canicola, estirpe LO4, utilizando o hamster (Mesocricetus auratus) como modelo biológico.

\section{Material e Método}

O inoculo infeccioso foi constituído por uma cultura pura de L. interrogans sorovar Canicola (estirpe LO4), autóctone e virulenta, isolada do fígado de um suíno de abatedouro em Londrina, Estado do Paraná ${ }^{17}$ e tipificada pela técnica de adsorção de aglutininas com o kit de anticorpos monoclonais no Royal Tropical Institute, Amsterdã, Holanda. O inoculo foi obtido a partir de macerado de rim e fígado de hamster, previamente inoculado pela via intraperitoneal com $1 \mathrm{~mL}$ de cultura de referência e eutanasiado no quinto dia pós-infecção. A diluição de trabalho foi a que apresentou 30 leptospiras por campo microscópico no aumento de 200 vezes. A determinação da $\mathrm{DL}_{50}$ do inoculo infeccioso foi efetuada de acordo com a metodologia de Reed e Müench ${ }^{18}$, inoculando-se cinco grupos de dez hamsters por via intraperitoneal com 0,2 mL de uma suspensão submetida a diluições seriadas na base $10\left(10^{-1}\right.$ a $\left.10^{-7}\right)$.

Foram utilizados 130 hamsters (Mesocricetus auratus), todos do sexo feminino, com peso corpóreo situado entre 80 e 100 gramas, mantidos durante todo o período experimental em biotério convencional. Os animais possuíam estado geral de saúde bom e foram mantidos em gaiolas de dez animais, forrados com 
serragem esterilizada e alimentados com ração comercial peletizada balanceada e água à vontade.

Os animais foram distribuídos em dois grupos de acordo com a via de inoculação, sendo 60 animais para o grupo de pele escarificada e 60 para o grupo de pele íntegra. A infecção experimental foi realizada pela deposição de $250 \mu \mathrm{L}$ de suspensão (30 leptospiras/campo) da estirpe LO4 na região abdominal não escarificada e na região abdominal previamente escarificada com lâmina de bisturi estéril, em uma área de 2 X $2 \mathrm{~cm}^{2}$. Como grupo controle, foram utilizados dez animais inoculados pela via intraperitoneal com $250 \mu \mathrm{L}$ da mesma suspensão.

Os animais foram observados duas vezes ao dia, durante 21 dias. Os animais que vieram a óbito foram necropsiados e colhidos assepticamente rins, fígado, sistema genital (útero e ovário) e cérebro. Os animais sobreviventes foram eutanasiados após 21 dias. Foram ainda colhidas amostras de soro sanguíneo por punção cardíaca para a pesquisa de aglutininas antileptospiras nos animais sobreviventes frente ao sorovar Canicola estirpe LO4, utilizando-se a técnica de soroaglutinação microscópica (SAM) de acordo com a metodologia da microtécnica descrita por Galton et al. ${ }^{19}$ e Cole et al. ${ }^{20}$.

Durante a necropsia, fígado, rins, genitais (útero e ovário) e cérebro foram retirados separadamente. Uma alíquota de cada órgão foi fragmentada e colocada em microtubo estéril e identificado. Adicionou-se aproximadamente $1 \mathrm{~mL}$ de meio EMJH modificado contendo os antibióticos 5-Fluorouracil e ácido nalidíxico nas concentrações finais de $12 \mathrm{mg}$ e $8 \mathrm{mg}$, respectivamente, por $100 \mathrm{~mL}$, em cada tubo, agitando-se vigorosamente em vórtex por 30 segundos. Em condições de assepsia na câmara de biossegurança, utilizando uma pipeta, $1 \mu \mathrm{L}$ de cada suspensão foi depositada sobre uma lâmina, levando-a ao microscópio de campo escuro (200X) para pesquisa direta da presença leptospiras.

Foi semeado aproximadamente $1 \mathrm{~mL}$ em $5 \mathrm{~mL}$ de meio de cultivo EMJH (DIFCO) modificado e com antibióticos e incubado a $30^{\circ} \mathrm{C}$. Após 24 horas, $1 \mathrm{~mL}$ desse cultivo foi inoculado em tubos contendo $5 \mathrm{~mL}$ de meio EMJH modificado sem antibióticos e Fletcher (DIFCO) e incubado nas mesmas condições. As leituras no microscópio de campo escuro (200X) foram realizadas semanalmente durante dois meses 9

Para a comparação da proporção de animais mortos por leptospirose nos grupos experimentais, foi utilizado o teste de qui-quadrado ou teste exato de Fisher ${ }^{21}$. A comparação dos animais positivos para a presença de leptospiras em órgãos, dentro de cada grupo experimental, foi realizada com o teste de McNemar para amostras relacionadas ${ }^{22}$. O nível de significância adotado foi de $5 \%$. As análises foram efetuadas com os pacotes estatísticos SPSS for Windows versão $13.0 \mathrm{e}$ EpiInfo versão 6.04 .

\section{Resultados e Discussão}

Dos 60 hamsters inoculados por exposição cutânea íntegra, em três animais não foi possível proceder à colheita de materiais, consequentemente, esses animais foram desconsiderados.

Todos os animais do grupo controle positivo da estirpe LO4, inoculados por via intraperitoneal ( $\mathrm{n}=$ 10), morreram devido à leptospirose de três a sete dias pós-inoculação e apresentaram lesões generalizadas características da doença. O exame de microscopia direta mostrou a presença da bactéria nos rins, fígado, genitais e cérebro.

Dos 60 animais expostos por escarificação cutânea, $59(98,3 \%)$ morreram, enquanto que apenas nove $(15,8 \%)$ dos 57 animais expostos pela pele íntegra morreram (Tabela 1). Todos os animais morreram em um intervalo de nove a 12 dias. Houve diferença significativa na proporção de óbitos entre animais escarificados em relação aos não escarificados ( $p<0,0001)$, demonstrando que a pele escarificada mostrou-se ser uma via mais eficiente na indução da doença do que a pele integra. Comparando as proporções de mor- 
Tabela 1 - Comparação entre hamsters (Mesocricetus auratus) expostos pela pele escarificada e pele íntegra com relação ao óbito por leptospirose pela Leptospira interrogans sorovar Canicola, estirpe LO4

\begin{tabular}{lcccc}
\hline & \multicolumn{4}{c}{ Tipo de exposição } \\
\cline { 2 - 5 } Evolução & \multicolumn{2}{c}{ Pele escarificada } & Pele íntegra \\
\cline { 2 - 5 } & $\mathrm{N}$ & $\%$ & $9 / 57$ & $\%$ \\
\hline Óbito & $59 / 60$ & 98,3 & $48 / 57$ & 15,8 \\
Portadores & $1 / 60$ & 1,7 & $57 / 57$ & 84,2 \\
\hline Total (\%) & $60 / 60$ & 100,0 & & 100,0 \\
\hline
\end{tabular}

$\mathrm{p}<0,0001$

tes entre as vias pele escarificada e intraperitoneal, não foi observada diferença estatística $(\mathrm{p}=1,000)$. Já para a pele íntegra, a proporção de mortes foi estatisticamente menor do que na via intraperitoneal ( $\mathrm{p}<$ 0,0001).

Era de se esperar que a proporção de hamsters infectados por leptospiras fosse maior em animais expostos por pele escarificada do que em animais inoculados pela pele íntegra, uma vez que naquele grupo foram rompidas as barreiras inespecíficas da pele que dificultam a penetração e consequente instalação de leptospiras no organismo. Macedo et al. ${ }^{6}$ obtiveram resultados semelhantes, observando que $80 \%(8 / 10)$ dos hamsters morreram após inoculação de $0,25 \mathrm{~mL}$ do sorovar Pomona por escarificação cutânea na face interna dos membros, sem, contudo, avaliarem a pele íntegra; os autores sugeriram que novas investigações deveriam ser conduzidas com a via pele escarificada, tendo em vista o grande sucesso desta no estabelecimento da leptospirose em hamsters, assim como a via intraperitoneal.

$\mathrm{Na}$ tabela 2 estão apresentados os resultados da comparação entre a evolução da leptospirose e a deteç̧ão de positivos em órgãos segundo o tipo de exposição. Um animal foi considerado positivo quando foram detectadas leptospiras em pelo menos um dos órgãos, no exame direto ou no cultivo bacteriológico. Nos animais expostos por escarificação cutânea, não houve diferença estatística, pelo teste de $\mathrm{McNe}$ mar, entre evolução da leptospirose e detecção de positivos em órgãos ( $p=1,000)$, ou seja, os resultados discordantes são decorrentes do acaso, significando que $98,3 \%$ dos animais morreram e foram positivos na detecção de leptospiras nos órgãos. Já nos animais

Tabela 2 - Comparação entre a evolução e o resultado da detecção de positivos em órgãos para a leptospirose pela Leptospira interrogans sorovar Canicola, estirpe LO4, segundo o tipo de exposição

\begin{tabular}{|c|c|c|c|c|}
\hline \multirow{3}{*}{ Evolução } & \multicolumn{4}{|c|}{ Tipo de exposição } \\
\hline & \multicolumn{2}{|c|}{ Pele escarificada ${ }^{1}$} & \multicolumn{2}{|c|}{ Pele íntegra ${ }^{2}$} \\
\hline & Positivo (\%) & Negativo (\%) & Positivo (\%) & Negativo (\%) \\
\hline Óbito & $59(98,3)$ & $0(0,0)$ & $9(15,7)$ & $0(0,0)$ \\
\hline Sacrificado (portadores) & $1(1,7)$ & $0(0,0)$ & $43(84,3)$ & $5(100,0)$ \\
\hline Total (\%) & $60(100,0)$ & $0(0,0)$ & $52(89,7)$ & $5(10,3)$ \\
\hline
\end{tabular}

${ }^{1} \mathrm{p}=1,000 ;{ }^{2} \mathrm{p}<0,0001$ 
expostos pela pele íntegra houve diferença significativa ( $\mathrm{p}<0,0001$ ), ou seja, a maioria dos animais não escarificados foram sacrificados e foi confirmada a condição de portador. Grande importância deve ser dada a esses animais, pois são eles que irão atuar na condição de disseminadores de leptospiras no meio ambiente e consequente transmissão da doença para outros animais e para o ser humano ${ }^{2}$.

De todos os animais portadores, $73 \%$ foram positivos para leptospiras nos rins, $42 \%$ no cérebro, $33 \%$ no fígado e $24 \%$ no genital, independentemente da via de inoculação. A presença das leptospiras no cérebro e no aparelho genital pode estar relacionada à fase imune da doença, que possui uma duração variável. Nesse período, as leptospiras desaparecem da circulação e do fluido cerebrospinal e localizam-se em áreas de privilégio imunológico, sequestradas do sistema imune: túbulos contornados renais, câmara anterior do olho, sistema nervoso central e aparelho reprodutor ${ }^{2}$.

No teste de soroaglutinação microscópica dos animais sobreviventes, apenas um animal do grupo não escarificado exposto a duas doses de 100 leptospiras/

\section{Referências}

1. BLAHA, T. Epidemiologia especial veterinária. São Paulo: Acribia, $1995.529 \mathrm{p}$.

2.FAINE, S.; ADLER, B.; PEROLAT, P. Leptospira and leptospirosis. 2. ed. Melbourne: MediSci, 1999. 272 p.

3. SANGER, V. L. Leptospira pomona infection in hamsters. Cornell Veterinarian, v. 51, p. 489-498, 1961.

4.SEMENOVICH, V. N.; POLOTSKÜ, Y. E.; DAITER, A. B.; KLEINERMAN, A. S. Relationship between leptospiras and the host during experimental leptospirosis in golden hamsters. Zhurnal Mikrobiologii Epidemiologii I Immunobiologi, v. 3, p. 76-82, 1988.

5. ARZUMANYAN, R. Pathogenicity of a leptospire strain isolated in Armenia for different animals (rabbit, guinea, pig, hamster, mouse, lamb, young bell). Zheernal Mikrobiologii Epidemiologii Immunobiologii, v. 44, p. $151,1967$.

6. MACEDO, N. A.; MORAIS, Z. M. de; CAMARGO, C. R. A.; ALVES, G. J.; AZEVEDO, S. S. de; NUMBERGER JUNIOR, R.; VASCONCELLOS, S. A. Influência da via de inoculação sobre o estabelecimento e evolução da leptospirose em hamsters (Mesocricetus auratus) experimentalmente infectados com Leptospira interrogans sorovar Pomona. Brazilian Journal of campo foi regente para Leptospira interrogans sorovar Canicola estirpe LO4 com título 200, demonstrando a baixa indução imune da estirpe LO4 nessa espécie animal. Marchiori Filho ${ }^{23}$ trabalhou com a estirpe LO4 com duas concentrações diferentes do inóculo infectante em várias vias e também não detectou soroconversão ou títulos de aglutininas até 21 dias pós-infecção em hamsters e destaca o baixo poder imunogênico pelas vias e concentrações estudadas, por não ser capaz de induzir altos títulos de anticorpos aglutinantes.

\section{Conclusões}

A via cutânea escarificada induziu maior letalidade quando comparada com a pele integra, sendo estatisticamente igual à via intraperitoneal, com estabelecimento e evolução da leptospirose em hamsters pelo sorovar Canicola, estirpe LO4. A via cutânea íntegra induziu mais frequentemente o estado de portador renal e/ou genital para leptospirose. O sorovar Canicola, estirpe LO4, induziu resposta humoral em apenas um animal inoculado, evidenciando seu baixo poder imunogênico.

Veterinary Research and Animal Science, v. 41, n. 3, p. 194200, 2004.

7.BÜRKI, F. Die Viruleng Von Leptospira Pomona - Strammen für den Syrischen Goldhamster. Veterinär Medizin, n. 9, p. 428-432, 1962.

8. KOLBER, M. Emprego do Hamster (Mesocricetus auratus) como modelo biológico para a indução da condição de portador renal de leptospiras. 2006. $124 \mathrm{f}$. Tese (Doutorado em Medicina Veterinária) - Faculdade de Medicina Veterinária e Zootecnia, Universidade de São Paulo, São Paulo, 2006.

9. MILLER, N. G. Observations of the carrier state in hamsters infected with Leptospira Interrogans serotype Pomona. Medical Microbiology and Immunology, v. 158, p. 1-8, 1972.

10.EZHKOVA, M. S.; KOTYLEV, O. A.; JONOVA, D. P.; SADYKOV, N. I.; SHOSKIN, V. A. Morphological and ultrastructural changes in the organs of animals (guinea pig and hamsters) infected with leptospirosis. Sbornik Nauchnykh Trudov, Kazinskii Veterinary Institut, v. 5, n. 4, p. 50-54, 1983.

11.SAPP, W. J.; SIDDIQUE, I. H.; WILLIAMS, C. S.; GRAHAM, T. Histopathological evaluation of livers of pregnant hamsters 
infected with Leptospira canicola. American Journal of Veterinary Research, v. 41, n. 7, p. 1288-1292, 1980.

12.PASSOS, E. C.; VASCONCELLOS, S. A.; ITO, F. H.; YASUDA, P. H.; NUMBERGER JUNIOR, R. Isolamento de leptospiras a partir de tecido renal de hamsters experimentalmente infectados com Leptospiras interrogans sorotipo Pomona. Revista da Faculdade de Medicina Veterinária e Zootecnia da Universidade de São Paulo, v. 25, n. 2, p. 221-235, 1988.

13. CAMARGO, C. R. A.; VASCONCELLOS, S. A.; MORAIS, Z. M.; NUMBERGER JUNIOR, R.; HEINEMANN, M. B. Pesquisa de leptospiras nos ovários, úteros e embriões de hamsters experimentalmente infectados e induzidos à condição de portadores renais, através do tratamento com o estolato de eritromicina. Arquivos do Instituto Biológico de São Paulo, v. 65, n. 1, p. 75-80, 1998.

14.BEY, R. Immunogenicity of whole cell and outer envelope leptospiral vaccines in hamsters. Infection and Immunity, v. 10, n. 5, p. 1051-1056, 1954.

15.DELBEM, A. C. B. Purificação, caracterização e avaliação da capacidade imunogênica do lipolissacarídeo (LPS) de Leptospira spp isolada no Brasil associado ao hidróxido de alumínio ou monofosforil lipídio A como adjuvantes. 2004. 117 f. Tese (Doutorado em Medicina Veterinária) - Faculdade de Medicina Veterinária e Zootecnia, Universidade de São Paulo, São Paulo, 2004.

16. HUHN, R. G. Immunity to leptospirosis: bacterins in dogs and hamsters. American Journal of Veterinary Research, v. 36, n. 1, p. 71-74, 1975.
17.FREITAS, J. C.; SILVA, G.; OLIVEIRA, R. C.; DELBEM, A. C. B.; MULLER, E. E.; ALVES, L. A.; TELES, P. S. Isolation of Leptospira spp from dogs, bovine and swine naturally infected. Revista Ciência Rural, v. 34, n. 3, p. 853-856, 2004.

18. REED, L. J.; MÜENCH, H. A simple method of estimating 50 percent end-points. The American Journal of Hygiene, v. 27, n. 3, p. 493-497, 1938.

19.GALTON, M. M.; SULZER, C. R.; SANTA ROSA, C. A.; FIELDS, M. J. Application of a microtechnique to the agglutination test for leptospiral antibodies. Applied Microbiology, v. 13, n. 1, p. 81-85, 1965.

20.COLE, J. R.; COLE JR., J. R.; SULZER, C. R.; PURSELL, A $\mathrm{R}$. Improved microtechnique for the leptospiral microscopic agglutination. Applied Microbiology, v. 5, n. 6, p. 976-980, 1973.

21.ZAR, J. H. Biostatistical analysis. 4. ed. Upper Saddle River: Prentice Hall, 1999. 663 p.

22.SIEGEL, S.; CASTELLAN JR., N. J. Estatística nãoparamétrica para as ciências do comportamento. 2. ed. Porto Alegre: Artmed, 2006. 448 p.

23. MARCHIORI FILHO, M. Indução do estado de portador renal e genital pela Leptospira interrogans sorovar Canicola, estirpe LO4, em hamsters (Mesocricetus auratus). Influência da concentração, da virulência da estirpe, da via de inoculação e da vacinação. 2007. $131 \mathrm{f}$ Tese (Doutorado em Medicina Veterinária) - Faculdade de Medicina Veterinária e Zootecnia, Universidade de São Paulo, São Paulo, 2007. 